University of Massachusetts Amherst ScholarWorks@UMass Amherst

Communication Department Faculty Publication

Series

Communication

2013

\title{
The cultural meanings of Israeli Tokbek (talk-back online commenting) and their relevance to the online democratic public sphere
}

Gonen Dori-Hacohen

University of Massachusetts - Amherst

Nimrod Shavit

University of Massachusetts Amherst

Follow this and additional works at: https://scholarworks.umass.edu/communication_faculty_pubs

\section{Recommended Citation}

Dori-Hacohen, Gonen and Shavit, Nimrod, "The cultural meanings of Israeli Tokbek (talk-back online commenting) and their relevance to the online democratic public sphere" (2013). International Journal of Electronic Governance. 95.

https://doi.org/10.1504/IJEG.2013.060649 


\title{
The cultural meanings of Israeli Tokbek (talk-back online commenting) and their relevance to the online democratic public sphere
}

\author{
Department of Communication, \\ University of Massachusetts, \\ 304 Machmer Hall, 240 Hicks Way, \\ Amherst, MA 01003-9278, USA \\ E-mail: gonen@comm.umass.edu \\ E-mail: nshavit@comm.umass.edu \\ Website: gonen@dori-hacohen.com \\ ${ }^{*}$ Corresponding author
}

Gonen Dori-Hacohen* and Nimrod Shavit

\begin{abstract}
Israeli journalistic websites have initiated a feature that became fairly universal: a section at the end of each article that allows readers to respond to the article and to each other. This feature is captured by the metacommunicative term 'tokbek', derived from the English phrase 'talk-back'. Although originally viewed as having the potential to promote civil participation, the tokbek soon became associated with pejorative cultural meanings that indicated its failure to do so. Drawing on the Ethnography of Communication, we provide an interpretative framework for an analysis of this failure. The main function of tokbek is the construction of the commenters' political identities, mainly as leftists and rightists. This oppositional construction takes the antagonistic form of a 'bashing ritual' that communicates radical pessimism about the possibility of political debate. Because sharing a virtual space does not necessarily facilitate deliberation, democratic culture should be explicitly addressed when discussing technological advancements.
\end{abstract}

Keywords: online public participation; online public sphere; online comments; ethnography of communication; democratic culture; terms for talk; kasha; electronic governance; talk-back.

Reference to this paper should be made as follows: Dori-Hacohen, G. and Shavit, N. (2013) 'The cultural meanings of Israeli Tokbek (talk-back online commenting) and their relevance to the online democratic public sphere', Int. J. Electronic Governance, Vol. 6, No. 4, pp.361-379.

Biographical notes: Gonen Dori-Hacohen is a discourse analyst and a communication scholar. He studies interactions and focuses on their interrelations with culture, politics, and the media. Currently he researches civic participation in Political Radio Talk, and other arenas of public participation, such as online comments.

Nimrod Shavit is a communication graduate student at UMass Amherst. Drawing on ethnographic and discourse analytic approaches he studies the faculty of human action with an emphasis on the political and ethical dimensions. 
This paper is a revised and expanded version of a paper entitled 'The cultural meanings of tokbek (talk-back) as a term for online political talk in Israeli public discourse' presented at the Ethnography of Communication: Ways Forward Conference, Omaha, NE, USA, 11-12 June, 2012.

\section{Introduction}

From its early inception, the Israeli internet has had a feature that only later became popular in other countries: the 'comments section' at the bottom of every article page, in which readers are able to respond to the article and to each other. Within the subgenre of internet journalism, such responses have come to be known in Hebrew as tokbek (sing.) or tokbekim (pl.). ${ }^{1}$ Israeli commentators who have addressed this phenomenon usually tell a story of 'glorious failure' that explains how the commenting feature had unprecedented potential to facilitate new modes of civil engagement with political events, but what emerged in practice was 'anti-discourse' (Kohn and Neiger, 2007) ${ }^{2}$ that undermined attempts at constructive dialogue. Thus, for many Israelis, tokbek has become a pejorative term. In this paper, we provide a cultural interpretative framework for this story of communication failure and the discursive practices it demarcates. In so doing, we stress the role of culturally inflected speech activities in the construction of technologically mediated public spaces and their related norms of interaction.

Our study begins with the premise that online participation is a situated activity. Thus we contend that socioculturally patterned communication practices cannot be overlooked when discussing technological advancements and their relevance to democracy. In this sense, we concur with Wilson and Peterson (2002, p.461), who argued that "Understanding local discourse and ideologies of media technology is crucial since speakers incorporate new technologies of communication from existing communicative repertoires, which influence new and emerging cultural practices".

Our exploration of the discursive framing and distinctive features of tokbek as a communicative practice and a ritualised discourse is based on the theoretical positions of the Ethnography of Communication (EOC henceforth) (Hymes, 1972), cultural communication (Philipsen, 1987, 2002) and cultural discourse analysis (Carbaugh, 2007). The central assumption within these approaches is that culture and communication are inextricable as culturally focal communicative events and expressive forms are analysed to elucidate the ways in which they both reflect and re-constitute cultural assumptions and social arrangements (Katriel and Philipsen, 1981). One of the ways that focal speech occasions and expressive forms are identified as culturally significant is through locating the use of culture members' meta-communicative 'terms for talk' (Katriel, 1986; Carbaugh, 1989). We therefore see the emergence of the term 'tokbek' as a metacommunicative attempt to establish a particular way of political talk in Israel.

In addressing questions of civil participation and political discourse, our approach is independent of the presuppositions of any democratic theory. As an ethnographic perspective, EOC views democracy as the ways cultural members perform, interpret, and negotiate the communicative practices they see as democratic (Townsend, 2009). Thus, the goal of theorising democracy and civic participation within this perspective is to provide an explanatory framework for the ways that culturally named and/or recognised 
discursive forms and speech activities, such as tokbek, make up the context for democratic participation in particular societies.

At the same time, we recognise the significance of abstract formulations such as "deliberative democratic public sphere" (Habermas, 1989) and 'agonistic pluralism' (Mouffe, 2000) to the theoretical understanding and critical evaluation of democratic participation and civic participation. Furthermore, we contend that situated explorations of democratic practices and their derivative theoretical constructs can contribute to the debates within and among these perspectives. However, in facilitating a conversation between political philosophical and situated sociocultural theories of democracy, we do not attempt to 'test' the former on the basis of the latter. Rather, we hope to provide an intertextual space of exchange for insights from the two research traditions.

Our primary theoretical goal is to provide a local explanation of tokbek as an Israeli way to "do civic participation online". Starting with a description of tokbek as a comment feature, we explore the meta-communicative process by which it was established as a pejorative term for political talk based on Carbaugh $(1989,2007)$, who suggested dimensions of cultural meaning about communication, personhood and social relations. We then analyse the situated cultural meanings of tokbek discourse as an interactional scene and argue that the main function of tokbek is to reconstitute paradigmatic personifications of oppositional political agendas as either leftists or rightists. Based on Philipsen's (1987) approach to cultural communication and Katriel's (2004) discussion of kasah ('bashing') as an emergent way of speaking in contemporary Israel, we propose the tokbek discourse as a 'bashing ritual'. After establishing this explanatory framework, we move to contextualise it within the broader discussion of online democratic participation. From the evaluative vantage point of both Habermas's (1989) discussion of the public sphere and Mouffe's (2000) formulation of agonistic pluralism, the tokbek ritual as currently enacted in Israel is detrimental to democracy. We conclude that in the absence of 'democratic culture', internet technologies cannot guarantee a platform for democratic participation.

\section{Data and methodology}

This study is based on aggregated readings of tokbek comments between 2010 and 2012 . Comments were collected from Ynet, NRG, and Haaretz Online, Israel's three leading journalistic websites. We focused both on opinion articles and news reports as their comments show little to no difference. We also conducted an in-depth analysis of a few hundred comments from "the most tokbeked news articles" (all three websites feature this category) between January and April 2012. Additionally, we analysed a couple hundred comments from an article published during the Second Lebanon War in 2006 that became renowned for breaking the tokbek record with more than 2500 comments. ${ }^{3}$ Finally, we collected a dozen articles about tokbek based on a Google search for the term 'tokbek'. These served as a sub-collection for the analysis of the meta-communicative construction of the tokbek as a term for talk.

Additionally, as Israelis who read tokbek comments from the point of view of the targeted audience, we kept on 'scavenging' for examples as the research developed. This scavenging could have been rationalised as random sampling; however, we took an ethnographic approach. Whenever one of us read a news article and found the attached comments meaningful (i.e., culturally salient from culture members' points of view), 
we added them to the corpus. The danger in using such a method, of course, is that it might lead one to collect only 'good' illustrations of the emerging research themes while neglecting less-supportive cases. We intentionally tried to avoid this tendency, which meant that at many points during the study we found ourselves perplexed by particular instances. However, these moments of confusion allowed us to fine-tune our analytic categories and reconsider our developing research themes.

Data analysis is based on the approaches associated with EOC (Hymes, 1972; Philipsen, 1987; Carbaugh, 1989, 2007) and addresses questions regarding the symbols, meanings and symbolic forms that constitute recognisable types of personhood, social relations, and communicative modes of exchange for the participants in tokbek discourse. In our translations of tokbek comments and journalistic commentaries about tokbek, we attempted to remain faithful to the original language of the authors. To academic readers, these translations may appear to include spelling mistakes and erroneous sentence structures (that at times are present in the original texts), as well as extreme registers and offensive word choices.

The comment feature that emerged in the context of News and Opinion articles was soon extended to every journalistic category (Travel, Culture, Relationships, etc). Because the interest of this study is online civic participation in terms of political debate, we focused only on comments from the first two categories. The phenomenon of online commenting extends far beyond the analytic categories discussed in this paper; ${ }^{4}$ nonetheless, we should remember that tokbek is first and foremost a term for political talk within Israeli public discourse.

Finally, we do not suggest that every tokbek or every news story in Israel that receives comments demonstrates all or even some of the features discussed below. Indeed, writers of online comments may utilise their responses for many other goals that are not analysed in this study (e.g., to use language in creative ways; preach and educate; state positions about various topics; and produce creative writing in the form of small-scale essays (cf., Hecht, 2004; Galily, 2008)). Still, we contend that the clusters of cultural meaning discussed below are essential to the tokbek phenomenon as a term for political talk and a form of political discourse.

\section{Tokbek as a cultural term for online political talk}

The term tokbek refers to a relatively simple technological feature that started in the mid1990s. This feature enables online users to post, in writing, their responses to media articles and to each other. Originally, Israeli websites did not term this feature 'tokbek'; rather, it was formally referred to as 'tguvot' (responses). Thus, our first analytical step is to reveal the embedded cultural significance of locally naming a digital communication feature with a unique cultural term.

In terms of webpage structure, the main news article is usually followed by a series of advertisements and a commenting template that invites readers to insert new responses. The actual comment thread appears below this commenting template (see Figure 1). As an organising unit for writing an online response, this commenting feature comprises certain elements. Each tokbek has a title line and a space for the commenter's name and place of residence. Below these spaces is a place to deliver the primary message of the response. Many users choose not to identify themselves and use the name space to deliver an additional part of their primary message (Klienke, 2008). 
Figure 1 The tokbek feature of the Israeli journalistic webpage ${ }^{5}$ (see online version for colours)

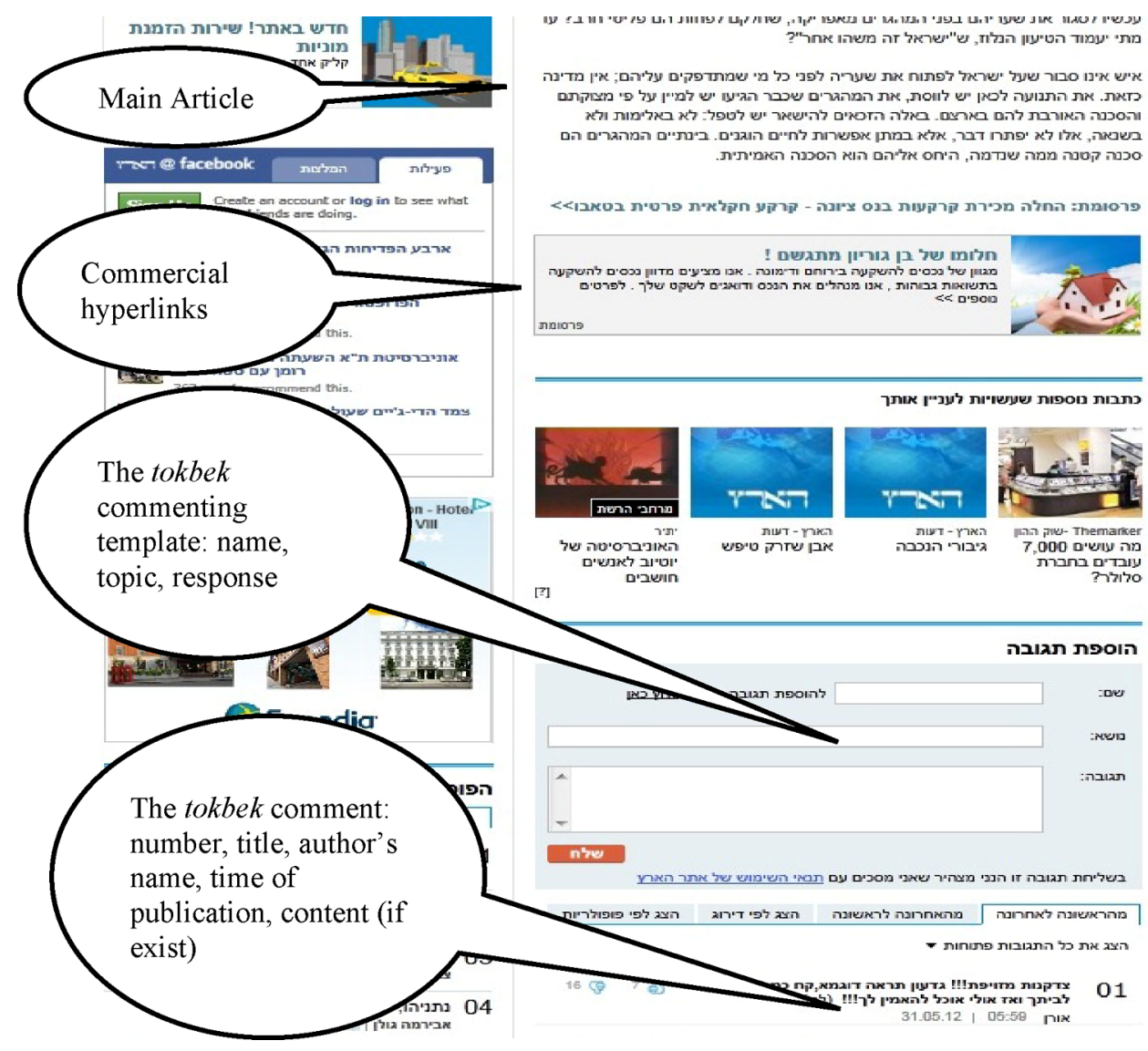

Semantically, the term tokbek is derived from the English noun phrase 'talk-back' that usually refers to US talk-radio. As written texts, tokbek comments lack the 'talking' element that is associated with the co-presence of radio conversation. Yet, their '(feed)back' element is heightened as they respond to the text above them. Whereas online communication is considered to be a hybrid of written and oral language (Kleinke, 2008), the proper interpretation of the tokbek discourse as a way of speaking is culturally salient in the term itself (Carbaugh, 1989). The notion of 'talking back' emphasises the relational structure of the interaction and captures the essence of the practice better than the neutral term 'tguvot' (responses). As we show in the following sections, the term 'tokbek' radiates cultural meanings not only about its status as an oral form of communication but also about the manner and tone of this particular type of communication. Furthermore, the quick adaptation of the term 'tokbek' into popular Israeli public discourse reveals linguistic transformations that bear cultural meanings not only about the communicative act itself but also about those who practice it as particular types of persons. ${ }^{6}$ Nowadays, Israelis can letakbek, i.e., "write tokbek comments"; an Israeli can be or become a tokbekist, i.e., "a person who writes tokbek comments"; and one can also act like a tokbekist, i.e., "respond in the fast and aggressive manner associated with the tokbek". 
The technological commenting features of tokbek evolve in response to technical difficulties and to social criticisms of tokbek discourse. Such changes include enabling registered readers to recommend others' responses, which has led to ratings of tokbek comments. Because tokbek discourse is often seen as over aggressive, some journalistic websites and individual journalists have decided to disable the response feature for certain articles. At one point, some websites even included commenters' IP addresses in the commenting feature as a preventive measure. However, none of these changes prevented tokbek from being perceived as rude, vulgar, and detrimental to online political discussions. In the next section, we describe how the pejorative meanings attached to the tone and manner of tokbek as an aggressive way of speaking and to the tokbekist as a vulgar type of person have been both established and challenged in the metacommunicative discourse of prominent public commentators as well as tokbek commenters in Israel.

\section{The meta-communicative construction of tokbek as pejorative term}

Initial commentaries about tokbek discourse were generally positive. A number of media commentators saw it as user-generated content that contributed to the traditionally vibrant political discussion within the Israeli public sphere. In 2003, Ofer Shelakh, currently a Knesset (Parliament) member but at that time a leading political commentator, noted that users' responses in the internet resemble "the nowadays town commons". ${ }^{7}$ With this metaphor, Shelakh proposed to see internet responses as a form of folk knowledge applied to the interpretation of everyday political life. Indeed, Hermida (2011) found similar attitudes when interviewing journalists both in Israel and elsewhere.

Notably, Shelakh attached this positive meaning of the commenting feature to the formal term 'tguvot' (responses). However, this positive evaluation changed rapidly, together with the transformation of tguvot into the cultural term tokbek. This culturallinguistic shift is evident in the following commentary from 2004 by Rogel Alper, the media commentator for the elite newspaper Haaretz, who introduced the term 'tok-bek' (with a hyphen):
(1) "The tok-bek gives every citizen a communication arena, immediate public advertisement of his response to current events. Everyone is turning to be a publicist. So what can go wrong? Well, one can learn something about the Israeli Zeitgeist from surfing the tok-bek: There is no one to talk to. The average Israeli of the tok-bek does not come to argue... He is violent, boisterous, decisive, threatening, simplistic, and has copyrights over the Truth and reality. The tok-bek is only allegedly a tool for promoting public debate on current events. In truth, most commentators are busy in silencing each other and denying the other legitimacy.",

In Alper's interpretation, the optimistic view of commentators such as Shelakh was premature. Indeed, the commenting arena has the potential to facilitate new modes of public participation, but in practice this participation reveals the cultural faults inherent to political debate in Israel. This negative interpretation is attached to the emergent term 'tokbek' and radiates particular meanings about the personhood of the participants and the tone and manner of the conversation. As a culturally recognised type, the tokbek commenter is heard as a narrow-minded brute who yells his or her opinion without any intention of engaging in a constructive dialogue. 
Other Israeli journalists followed this normative-interpretative framework, and started distinguishing between tokbek writers and the rest of 'the public'. As Ben Caspit, another prominent columnist wrote: "The public is not stupid. It has no relations to the tokbek writers flock [adat tokbekistim] who discharge their embitterment on everything published about a topic". ${ }^{9}$ Both Alper and Caspit point to one major problem with tokbek as political discourse: it does not represent public opinion or constitute an adequate arena for public discussion. This position is shared by other journalists who do not see participatory journalism as helpful to democracy (Hermida, 2011).

However, from the commenters' point of view, tokbek discourse radiates other meanings about the society in which they live and operate. In terms of social relations, these meanings refer to an assumed power difference between 'the people' ( $h a^{\prime}$ ' $\left.\mathrm{Am}\right)$ and 'the elite' (to which public commentators such as Alper and Caspit belong) that governs media and academic institutions. This opposition usually implies political affiliations whereby the 'elite' is associated with the left-wing while 'the people' are members of the right-wing.

Within this assumed power relation, the commenters see themselves as inferior and therefore deprived of voice. This view posits 'the establishment' in a direct opposition to the tokbek commenters who deploy the commenting feature as a public stage to express their frustration in the form of anti-discourse. Whereas the media presents an elitist 'civilised tone' in covering 'the truth', the tokbekists write in a highly emotional and aggressive tone what they see as the 'silenced truth'. Thus, the censure speech of many tokbek comments is directed against haTikshoret (the Media) to accuse it of being unproportionally leftist and thus "too critical of the government" (usually a right-wing government). A typical example is the following comment that addresses other commenters with the accusation that the media is 'brainwashing' the public opinion with a Leftist agenda: "The left-wing media brainwashed you, and now you repeat the same moronic clichés". ${ }^{10}$

Following the discussion of Kohn and Neiger (2007), the anti-discourse of tokbek commenters that is directed against the authors of journalistic articles (i.e., 'anti-ethos') may be based on the above rationale. However, censuring the speech of this or that journalist is not the main function of tokbek as a verbal scene for civic participation. Rather, tokbek discourse revolves around the commenters' responses in the framework of a political debate. In this interactional context, the anti-discourse that the term tokbek demarcates reveals further situated meanings in terms of communication, personhood, and social relations. We address this cluster of cultural meanings in the following section.

\section{The cultural meanings of tokbek discourse as political debate}

In our reading of tokbek discourse as an interactional scene, we easily identified two recurring oppositional terms that mark paradigmatic personifications of political agendas: the leftist and the rightist. These identity categories are mutually constitutive through various rhetorical and linguistic forms. Some of these are direct expressions of opinion that include politically recognisable mock names, terms, and idioms. The following comment can be seen as a typical case: 
(2) Moron rightists. How your Bibi is lying in your faces and pisses on your heads from the balcony. (n"c)

Bentzi A, 21/02/12 10:35

This tokbek has no content, just a title line and the commenter's name. The commenter does not address the author of the news report to which his comment is attached but rather the generic public within the right-wing camp. Functionally, this commenter achieves two goals. First, he constructs his oppositional identity as a member of the leftwing camp or leftist by referring to right-wing members as rightists and 'morons' and by using Israeli Prime Minister Benjamin Netanyahu's nickname 'Bibi' in a pejorative register. Second, he provokes right-wingers by saying that 'their' prime minister easily manipulates them. Thus, the sole consequence of the comment, which is heard as an offensive slur, is the posing of an identity boundary between the oppositional camps without any attempt to engage in further conversation. If there is an argument here it is simply this: right-wingers are idiots.

While the above commenter uses highly emotional language, a self-presentation of leftist persona does not require such a tone as the following example indicates:

\section{(3) How they erased the Nakba from our consciousness}

"We didn't know" is a known slogan, 30/01/12 13:01

"We didn't know" is a known slogan. Until today there are Germans who deny the Holocaust... So there are Israelis who do not believe there was Palestine and that we are responsible for the Nakba, which for the Palestinians is a trauma exactly like the Holocaust to the Jews. In Ilan Pappe's book, about the ethnic cleansing of Palestine, a full chapter is dedicated to how they suppressed the Nakba in the Israeli Public consciousness and history... The process of understanding what happened in Palestine that turned it to the enemy of Israel is very painful, but is essential in order to move forward and to end this eternal war." 12

This commenter constructs a leftist identity, starting with the use of the Arabic term 'Nakba' (the Catastrophe), i.e., the Palestinian term for the Israeli 'War of Independence'. Because usually members of the radical left use this term in the Israeli political discourse, it serves here as an indexical marker of a leftist identity. In terms of content, this tokbekist compares the Israeli denial of the Nakba and the phenomenon of Holocaust denial to argue that both are equally preposterous. On top of comparing Israel to Nazi Germany, this tokbekist uses other symbols to construct her leftist identity. She refers to the renowned Israeli historian Ilan Pappe, who is considered to be a member of the radical left-wing and an icon of the leftist agenda in Israel; and calls for an end 'the eternal war', a slogan that is associated with the Israeli left-wing 'peace camp'.

It is tempting to argue that this tokbek demonstrates a discourse of rational argumentation. While there might be some truth to it, the significance of this tokbek lies elsewhere. For the average Israeli reader, this tokbek regurgitates known leftist clichés. For example, the statement "We didn't know' is a known slogan", which refers to the Nuremberg trials, is itself a known slogan in the Israeli public discourse. While this seemingly rational style goes against the usual aggressive-abusive tone of the usual tokbek, within the framework of this comment, arguing that the other side of the political isle is equivalent to the Nazis is heard as an extreme claim and therefore can be taken as an offense. Moreover, as the stereotype goes, elitist leftists use to think of themselves as more educated than their right-wing counterparts and therefore more rational. In this 
sense, the rational style of this tokbek becomes another index for the commenter's political identity. Rather than offering a situated interpretation of current events, this commenter too focuses on declaring her oppositional leftist identity.

Quite expectedly, the opposition between leftist and rightist types of personhood is maintained in the construction of rightist identities. One example can be seen in the following comment that responds to a decision by Israel's attorney general to evict settlements in the Occupied Territories, a decision to which right-wing political parties were opposed:

\section{(4) The Attorney General}

Israeli, 21/02/12 10:21

should better look for a new job. The left vanished with its diasporic theories. In the last elections the People voted for the Land of Israel and not for the Media parties and the leftist slivers. $^{13}$

This commenter calls for the firing of the attorney general, stating that the left disappeared since the right-wing party won the elections with its policy of maintaining the biblical-historical 'Land of Israel' that includes the Occupied Territories. Notably, he contrasts this religious territorial notion with the leftist agenda of diaspora. This opposition refers to a popular rightist accusation of 'leftist defeatism'. In this view, leftists are 'anti-nationalist' as they are willing to give up on the Jewish state and return to the days when Jews were in exile. Thus, similarly to the left-wing commenters analysed above, this tokbekist utilises his comment to express his identity as a rightist who despises the opposite camp.

As these examples indicate, the main function of tokbek comments is to declare the commenters' political affiliations through condemnations of the other camp, usually in a highly expressive way. More than providing a resource for further political debate, this type of tokbek serves as slogans or demonstration signs. As provocative statements of identity, tokbek comments radiate another set of meanings about the status of communication with members of one's oppositional camp. Tokbekists consistently condemn their counterparts as insane, which leads participants in the Israeli tokbek scene to accuse each other of lacking referential abilities. While accusations of insanity are widespread in tokbek comments, members of each political camp ascribe a specific type of mental deficiency to their opponents. The following are some typical cases:

(5) What a joy to read the responses of the psycho right. Oh what a joy.

stressed out, ha? 21/02/2012 10:15

In this comment, a leftist expresses his joy at the distress of the right-wing members in a mocking tone, using the term meturlal (psycho). In the tokbek discourse, the term 'psycho' connotes an extreme degree of violence and is intimately associated with another term for personhood, the notorious fascist, frequently used by leftists to portray their rightist opponents. In this stereotype, right-wing activists are seen as fanatics who build settlements and use violence to achieve their political goals. Rightists are 'psychotic fascists' in the sense that they fail to recognise fundamental humanist values and the very limitations of reality.

(6) How delusional to support the idea of destroying Israel

Sane grandma 12:25 $31.01 .12^{14}$ 
As apparent from this comment (6), the rightists in their turn evoke another class of insanity charges. This commenter accuses leftists of wanting to destroy Israel, calling their agenda 'delusional'. Hazuy, the Hebrew word for delusional, is associated in this context with the leftist ideal peace. As the popular rightist argument goes, the leftists fail to see the reality of the conflict between Israel and the Arab nations, especially the Palestinians, because they are blinded by their utopian vision of peace. This delusion is dangerous to the very existence of the Israeli state, and as long as the leftists choose to remain blinded by their convictions, talking with them will make no sense. The sanity discourse is also evident in the playful nickname that this commenter uses, 'sane grandma', that refers to an allegedly sober view of reality. This view suggests an opposition between the rightist understanding of national security and the leftist naiveté as divorced from this reality.

And so, the oppositional model that organises the tokbek discourse as political debate reveals a fundamental schism in the Israeli society. The rightist and the leftist types of personhood have nothing in common in terms of a shared history and sentiments for the state. As summarised in Table 1, each side conceives of the other in the extreme and therefore as leading to the destruction of the Israeli society.

Table 1 The semantic field of opposition between leftists and rightists

\begin{tabular}{lll}
\hline Personhood & Leftist (as portrayed by rightists) & Rightist (as portrayed by leftists) \\
\hline Section of population & Elite & Commoner (ha'Am) \\
Historical comparison & Diaspora Jews & Fascists (Nazis) \\
Nationalism & Too little: dissolving the national & Too much: expanding the state to \\
& state & its destruction \\
Sentiment & Peaceful and naïve & Violent and murderous \\
Insanity type & Delusional & Psychos \\
\hline
\end{tabular}

Whereas tokbek discourse is post-moderated and a few comments are erased by website authorities, the comments presented above and many others like them were treated as worthy of publication and therefore legitimate. In terms of cultural salience, these are not extreme cases but representative ones; they adequately capture the clusters of meanings that the term 'tokbek' denotes in its common usage. In this respect, it seems that the tone, manner, and function of Israeli tokbek are very different from those of similar comments in the website of the British newspaper The Guardian. ${ }^{15}$

As apparent from the analysis so far, in the Israeli case, the main function of tokbek is to declare a political identity either a leftist or rightist. We denominate this phenomenon as 'inverted identity politics'. Usually, the concept 'identity politics' refers to political activity based on a particular social identity (e.g., 'being a woman' or 'being a Latino'). However, in the case of tokbek discourse, identities are not a means of initiating further political action but rather become the 'ends' of politics in both senses that Hymes (1972) gave to this term; the goal of the political action (i.e., a tokbek post) is to present an identity, and most likely there will be no outcome beyond this presentation. ${ }^{16}$ 


\section{Tokbek discourse as bashing ritual}

Our approach to the form and function of tokbek discourse is based on Philipsen's (1987, 2002) framework of cultural communication. A basic assumption of his perspective is that social integration is constituted and negotiated in and through communicative practices. That is, communication has a functional role in establishing the normative and cultural codes by which individuals become members of their community. This 'communal function' of cultural communication is structurally organised in terms of symbolic forms (ritual, myth, social drama, etc). From this perspective, the question is the following: How does the tokbek function of inverted identity politics serve to establish a shared space for civic participation in Israel?

The form of exchange we find in tokbek discourse constitutes a readily recognisable type of 'communicative ritual', i.e., a "communication form in which there is a structured sequence of symbolic acts, the correct performance of which constitutes homage to a sacred object" (Philipsen, 1987, p.250). However, as our analysis indicates, the tokbek ritual is unique in the sense that it symbolises the radical absence of a 'sacred object', i.e., an organising normative principle to which the participants adhere. Thus, the tokbek ritual reveals a contradiction between content and form because within it, social integration is organised around a shared sense of disintegration.

The tokbek ritual starts with an initial act of 'political statement' that carries necessary commentary about the political identity of the writer. The next move, which establishes the ritual framework, is a 'derogatory identification' that includes an explicit attempt to condemn the other side on the grounds of being either a leftist or rightist. From this point on, an exchange of insults and counter-insults follows. This sequence, which takes the back-and-forth structure associated with arguments or fights more generally, duplicates and amplifies the second ritual move and has a potential to continue ad infinitum. In effect, it does just that if we are to identify the scope of the tokbek as a single discourse that cuts across situated occurrences.

A paradigmatic example of this ritual sequence can be seen in the following thread (7): ${ }^{17}$

\begin{tabular}{|c|c|c|}
\hline 1 & Commenter 1 & I am so happy I didn't go to learn in your leftist college. \\
\hline 2 & Name & Communication student, Afula (24.04.12): \\
\hline 3 & Content & $\begin{array}{l}\text { Explain to me how the most leftist college is located specifically in } \\
\text { Sderot? }\end{array}$ \\
\hline 4 & Commenter 2 & > What is this happiness?? \\
\hline 5 & Name & Dan Shayish, (24.04.12): \\
\hline 6 & Content & Communication student, \\
\hline 7 & & $\begin{array}{l}\text { In your going out against the left without a reasonable presentation of the } \\
\text { topic reveals a thick, stupid, and square student }\end{array}$ \\
\hline 8 & & $\begin{array}{l}\text { I assume there is not even one academic establishment in the country } \\
\text { that would have admitted such a vagabond }\end{array}$ \\
\hline 9 & & $\begin{array}{l}\text { And if you were admitted to any academic establishment, your mere } \\
\text { admission points to the nullity of that establishment }\end{array}$ \\
\hline & & Be well and eat until you vomit the fascist laws of Israel \\
\hline & & Beytenu - sorry not fascist these are just the N.K.V.D \\
\hline
\end{tabular}


Commenter $3>$ And it clears there is no need to explain how a narrow-minded brute learns in Afula? (n"c)

12 Name Scared Jew (24.04.12)

13 Commenter $4>>$ Narrow-minded is the one who is not opened to the Arabs?

14 (No) name (24.04.12):

15 Content Broad-minded as opposed to him is he whose knowledge in who he is perplexed (sorry complicated) with his parents and spit his complexities on his people who are not his own [sic]. important. You ridiculed the Essence and gave up on it.

The first commenter ( $7: 1-3)$, who presents himself as 'communication student', responds to an article by a college professor who expresses a left-wing position. This comment exemplifies a second ritual move whereby the commenter shifts the focus from the writer's opinion to her identity as a leftist. Further identity claims are based on the association between the article writer and the college in which she teaches, which is therefore referred to as the 'leftist college', and the contradiction between this institution and its geographic location in a place that is often a war zone - Sderot, next to the Gaza Strip (7:3). Thus, the commenter establishes his identity as a rightist in the framework of this political discussion.

The next commenter demonstrates the typical progress of the ritual. He directly responds to 'the student' in a similarly aggressive tone and manner, accusing him of expressing undue happiness for not studying at that college (7:4) and criticising him for not making a valid argument in his comment. Not making any constructive argument himself, he embarks upon name-calling, referring to 'the student' as "thick, stupid, and square" (7:7). He continues with another personal insult, suggesting that the commenter is too stupid to be a 'real student' (7:8) and that if he is indeed a student, his institution does not deserve to be called academic (7:9). He finishes up with another insult, using the graphic image of vomiting and calling 'the student' a fascist. This insult is heightened by a reference to the NKVD, the Soviet secret police before the KGB (7:10). Ironically, by accusing his rightist interlocutor of being anti-democratic, this commenter establishes an oppositional identity of a leftist in a way that mirrors the discourse he seeks to condemn.

The next commenter (7:11-12), another leftist, continues the censuring style of the conversation. Similarly to the commenters before him, he embarks upon name-calling and accuses the above rightist commenter to be a 'brute' and a narrow-minded person (7:11). He then associates these personality traits with the commenter's hometown of Afula, a peripheral town in central-northern Israel that has a low economic and educational status, thereby evoking the opposition between left-wing elitists and rightwing commoners. As in the previous comments, the tone of this comment is heard as abusive and no attempt at dialogue occurs.

The last commenter in this excerpt demonstrates the repetitive structure of the ritual (7:13-19). This rightist commenter insults the previous leftist commenter (7:11-12), ironically asking him if broad-minded people are those who support the Arabs (at the 
expense of the Jews, as leftists usually are accused of doing). He then calls the leftists 'uprooted', linking their identity to the pejorative image of the Diaspora Jew (7:16). This character of the leftist person is constructed in opposition to the rightist who has knowledge about his own heritage and nation. Then, associating his identity with the religious-rightist camp, he repeats a biblical verse about trusting God (7:17) and finishes up with the accusation that because leftists gave up on God they have no origin and therefore no current essence (7:18-19).

As apparent from the above analysis, the integrative function of the tokbek ritual is based on a bashing tone and the exchange of direct 'bold-on-record' insults with no redressive action and no consideration of one's interlocutors' 'face wants' (Goffman, 1967; Brown and Levinson, 1987). The form and style of this ritual exchange is associated with what Katriel $(1986,2004)$ has identified as kasah (bashing talk) in contemporary Israeli public discourse. In her words:

\begin{abstract}
"The term kasah and its various derivatives... are commonly found in everyday parlance and in the press... Forceful speech marked as kasah does not carry the attenuating impact of a shared, legitimating code. Rather, it is interpersonally directed as a put-down, unmitigated by the invocation of a cultural frame that might warrant its aggressiveness. Kasah as brute force tends to be associated with the growing factionalism and radicalisation of Israeli social life, which implies an absence of a consensual system of symbols and meanings." (Katriel, 2004, p.208)
\end{abstract}

In this analysis, the emergence of kasah as a mode of civic engagement in Israel is directly related to the diminishing of the Zionist ethos marked by the Israeli style of 'straight talk', which is natively known as dugri speech (Katriel, 1986). In the constitutive years of the Israeli state, dugri speech, with its emphasis on simplicity, factuality, and functional transparency, signified the shared values and beliefs of Israeliborn Jews of European descent, the Sabras (Katriel, forthcoming, p.11). In Zionist ideology, according to Katriel, the Sabra identity as a New Jew was constructed out of a rejection of Diaspora Jewish logocentricity, self-effacing and appeasing attitude, and cultural preference for indirectness and verbal virtuosity. This fundamental rejection, which was grounded in a revolutionary, action-centred ethos, gave rise to Sabra culture (Katriel, forthcoming, p.10). According to Katriel, while being a bold on-record interaction style, dugri speech was traditionally warranted for Sabra speakers by a cluster of socio-historically situated meanings. These include assertiveness, sincerity, naturalness, and, most important to our discussion, solidarity, a social state characterised by an equalising 'we-feeling' (Katriel, forthcoming, p.11).

Following the growing cultural heterogeneity of Israeli society, the consensus surrounding the cultural position of dugri has diminished (Katriel, 2004, pp.196-197). The emergence of kasah as bashing discourse is one result of this process. As a "roughening of the dugri speech" (Katriel, 2004, p.205), it operates in the absence of the previously shared cultural and normative code to warrant its face-threatening enactment. The underlying metaphor of the style of kasah is that of a boxing match; in the interpersonal domain, it implies a forceful, aggressive verbal blow aimed at one's interactional partner. As such it is associated with the power-orientation that grounds contemporary Israeli militaristic values (Katriel, 2004, p.208).

Based on this view, we see the online public discourse marked by the cultural term 'tokbek' as a kasah fest that communicates radical pessimism about its very communicability. The mutual constitution of the leftist as delusional (hazuy) and the 
rightist as psycho (meturlal) leaves very little space for dialogue, and attempts at such dialogue ordinarily transform into an exchange of insults. Somewhat paradoxically, the communicative premise that the participants in this ritual share is that no communication can take place between their two groups. Thus, the tokbek ritual demonstrates an impossibility of reaffirming the relationship of the participants to a culturally sanctioned 'sacred object'.

The cultural void around which the tokbek organises is complemented by and balanced against a communicative excess in the form of endless exchange of predictable blows. The result is a frozen state of sociopolitical meltdown, a status quo that simulates a highly involved and lively debate while vacating the conditions for political action, change, or even dialogue. Thus, the tokbek ritual finds its place beside other cultural forms of talk which are detrimental to democratic participation in Israel, such as the 'griping ritual' that dissolves the participants' sense of political agency (Katriel, 1999). The absence of shared sanctified commitment to democratic values, what we see as 'democratic culture', therefore becomes a factor in the analysis of public participation in Israel and beyond. We turn next to consider this theme within the broad theoretical discussion of online democratic participation.

\section{Political culture and the online democratic public sphere}

Our study of tokbek corresponds with the broader discussion of the limitations and possibilities of an online democratic public sphere on at least two levels. First, it can be evaluated from the vantage point of prominent political theories of democracy (Habermas, 1989; Mouffe, 2000). This approach resonates with what Carbaugh (2007) termed 'the critical mode' of an ethnographic investigation. Such an evaluation is useful because it supplements the ethical impulse of those who are concerned with the function of tokbek as anti-discourse in Israel. Second, the cultural analysis of the tokbek as online form of civic participation problematises the premises of some technologically oriented approaches (cf. Dahlberg, 2007). In this way, we attempt to show how a situated theory of cultural communication may serve as a critical resource in the evaluation of less-context-sensitive approaches.

Starting with Habermas's (1989) approach to democratic deliberation, it can be easily argued that the online tokbek communication scene fails to meet the conditions of what he sees as a democratic 'public sphere', i.e., a communication space of rational deliberation in which private individuals assemble into a public body to discuss and criticise the conduct of their government. Keeping in mind the tone and manner of the tokbek ritual, it would be almost absurd to seriously evaluate it in Habermas's terms. However, we do think that one point is noteworthy here, namely the Habermasian emphasis on the transformative quality of the debate. The main premise of Habermas's approach is that democratic deliberation is the process of shaping a public opinion in terms of consensus making. In this view, the main failure of tokbek discourse is its rigidity. Tokbek commenters enter the conversation with highly formalised political convictions to the degree of banal slogans. The mode of civic participation thus takes the form of a public demonstration in which opponents from the oppositional camps wave their signs and yell their slogans at each other. In this ritualised mode of engagement, no consensus can ever be reached and the communal function of the communication is to maintain an apparent social schism between the participants from each camp. 
The aggressive manner and passionate tone of the bashing ritual with its accent on disunity and resistance to consensus brings the discussion closer to Mouffe's (2000) approach of agonistic pluralism. This approach rejects the Habermasian ideal of rational consensus and theorises democracy as domesticated warfare, in which adversaries make necessary compromises in the form of tentative suspensions of hostilities. However, upon closer examination we see that Mouffe too does not give up on a consensual democratic alignment. In her view, democracy is essentially dependent on communal "forms of citizenship identification". Such forms of life necessitate sacred or foundational knowledge or beliefs according to which passions can be mobilised around democratic objectives (Mouffe, 2000, p.16).

In terms of cultural communication, Mouffe's view of a democratic ethos is realised in a speech style that sanctifies a consensual system of democratic symbols, meanings, and norms of interaction. Our analysis shows that tokbek as a bashing ritual fails to demonstrate democratic ethos in this sense. To use Mouffe's terms, in the case of the tokbek ritual we do not see an 'agonistic' relation among participants in which one's opponent is perceived as an adversary, i.e., one with whom the commenter has some common ground because they "share adhesion to the ethico-political principles of liberal democracy: liberty and equality" (Mouffe, 2000, p.15). Rather, the bashing relation between the participants is closer to her 'antagonistic' model whereby one's opponent is perceived as an enemy to be admonished and silenced.

Israeli tokbek as non-functional antagonistic public space can thus be seen as an extreme case of what Kersting (2012) calls 'Demonstrative Democracy'. In the demonstrative democratic model, no transformative action takes place as citizens use the public space to demonstrate their political affiliations without experiencing the back-andforth of a political deliberation that may lead to changing their opinions.

Cultural and political interpretations of the tokbek ritual as an online form of demonstrative participation have further implications for the study of democracy and technology. Although we lack the space to recount the entire discussion of the relations between the internet and the public sphere (cf. Bohman, 2004), we , similarly to Wright and Street (2007), would like to respond to approaches that accept the internet medium wholesale without paying attention to other social and cultural factors. These studies, although they provide sophisticated analysis of internet technological platforms, may overestimate the potential of the internet to constitute a "true democratic public sphere" (cf. Dahlberg, 2007) that provides an arena for everyday political talk (Graham, 2008). As we have attempted to show, the role of cultural codes for democratic participation is essential to the relation between technology and democracy. The availability of technology does not guarantee the emergence of a democratic culture. Rather, as our analysis of tokbek indicates, it may very well work the other way around and cultivate existing non-democratic modes of interaction. We therefore join the view that emphasises cultural variation in the distribution and adaptation of internet technologies (Wilson and Peterson, 2002, p.454).

\section{Conclusion}

The Israeli tokbek as an example of what scholars term 'the commentsphere' (Mishne and Glance, 2006) presents a rather pessimistic view of the internet as a vehicle for online democracy (Verger and Hermans, 2008). Indeed, online commenting as public 
participation in Israel seems to be detrimental to democracy as viewed by both Habermas and Mouffe. However, by making this claim we do not intend to imply that internet technologies are incapable of promoting a democratic public sphere. As Wright and Street (2007) have illustrated, the analysis of democratic deliberation should go beyond the internet medium to consider such factors as the design of the webpage and the organising principle of the discussion. We took a similar empirical approach to the study of online political discussion (cf. Monnoyer-Smith and Wojcik, 2012) and emphasised the cultural-communicational elements that govern tokbek discussion. From this sociocultural prism, we argue that the unique dispositions of Israeli political culture as realised in tokbek as both a cultural term for talk and an interactional scene denotes discursive practices that lead to communicative failure. This finding does not exclude the possibility of a transformative deliberation in the commentspheres of other societies, or in other contexts of online civic participation in Israel. We do, however, argue that in the Israeli case such instances are not captured by the term 'tokbek' in its common usage.

Our cultural argument keeps the door open for those who attempt to utilise digitally mediated technologies to promote public discussion in cultures in which democratic ways of living are well established (e.g., as Graham (2012) described the UK). Alternatively, political agents in societies that do not adhere to democratic values may find the internet and its features beneficial as a venue for promoting social change (such claims were made, although not fully established, about the Arab Spring). However, in contemporary Israel, the tokbek feature is far from promoting a democratic public sphere. It may be the case that other Israeli online platforms for civic engagement, such as political forums and blogs (cf. Vaisman, 2009) will reveal different ways of talking politics. Indeed, a systematic comparison between such venues may lead to a broader understanding of the speech economy that organises the political life in Israel.

\section{Acknowledgements}

We are in debt for Xima Avalos, Shawn Shimpach, Claudio Moreira, Demetria Shabazz, and Martha Fuentes-Bautista, who read and commented on prior versions of the paper, as well as to the two reviewers. The remaining short-comings are solely ours. The paper was partially funded by the Fellow Research Grant, University of Massachusetts, Amherst, and the University of Massachusetts, Amherst Mellon Mentoring fellowship micro-grant.

\section{References}

Bohman, J. (2004) 'Expanding dialogue: the internet, the public sphere and prospects for transnational democracy', in Crossley, N. and Roberts, J.M. (Eds.): After Habermas: New Perspectives on the Public Sphere, Blackwell, Oxford, pp.131-155.

Brown, P. and Levinson, S. (1987) Politeness: Some Universals in Language Usage, Cambridge University Press, New York.

Carbaugh, D. (1989) 'Fifty terms for talk: a cross-cultural study', International and Intercultural Communication Annual, Vol. 14, pp.93-120.

Carbaugh, D. (2007) 'Cultural discourse analysis: communication practices and intercultural encounters', Journal of Intercultural Communication Research, Vol. 36, No. 3, pp.167-182.

Dahlberg, L. (2007) 'Rethinking the fragmentation of the cyberpublic: from consensus to contestation', New Media and Society, Vol. 9, pp.827-847. 
Galily, Y. (2008) 'The (re) shaping of the Israeli sport media: the case of talk-back', International Journal of Sport Communication, Vol. 1, No. 3, pp.273-285.

Goffman, E. (1967) Interaction Ritual, Anchor Books, New York.

Graham, T. (2008) 'Needles in a haystack: a new approach for identifying and assessing political talk in non-political discussion forums', Javnost - The Public, Vol. 15, No. 2, pp.17-36.

Graham, T. (2012) 'Beyond 'political' communicative spaces: talking politics on the wife swap discussion forum', Journal of Information Technology \& Politics, Vol. 9, No. 1, pp.31-45.

Habermas, J. (1989) The Structural Transformation of the Public Sphere: An Inquiry into a Category of Bourgeois Society, MIT Press, Cambridge, Mass.

Hecht, J. (2004) 'Online discourse and a social medium', Internet Association Magazine, Last Retrieved on 11/02/2013 from www.isoc.org.il/magazine/magazine4_8.html 11/02/2013

Hermida, A. (2011) 'Fluid spaces, fluid journalism: the role of the 'active recipient' in participatory journalism', in Singer, J.B., Domingo, D., Heinonen, A., Hermida, A., Paulussen, S., Quandt, T., Reich, Z. and Vujnovic, M. (Eds.): Participatory Journalism: Guarding Open Gates at Online Newspapers, Blackwell Publishing Ltd, pp.177-191.

Hymes, D. (1972) 'Models of the interaction of language and social life', in Gumperz, J.J. and Hymes, D. (Eds.): Directions in Sociolinguistics, Basil Blackwell, New York, NY, pp.35-71.

Katriel, T. (1986) Talking Straight: Dugri Speech in Israeli Sabra Culture, Cambridge University Press, Cambridge, UK.

Katriel, T. (1999) 'Griping as a verbal ritual in some Israeli discourse', in Carbaugh, D. (Ed.) Cultural Communication and Intercultural Contact, Erlbaum, Hillsdale, NJ, pp.99-113.

Katriel, T. (2004) Dialogic Moments: From Soul Talks to Talk Radio in Israeli Culture, Wayne State University Press, Detroit.

Katriel, T. (forthcoming) 'Directness revisited: towards a socio-pragmatics of truth-telling', in Capone, A. (Ed.): Perspectives on Pragmatics and Philosophy, Springer.

Katriel, T. and Philipsen, G. (1981) "What we need is communication': 'communication' as a cultural category in some American speech', Communication Monographs, Vol. 48, No. 4, pp.301-317.

Kersting, N. (Ed.) (2012) Electronic Democracy, IPSA Series The World of Political Science, BB, Opladen.

Kleinke, S. (2008) 'Emotional commitment in public political internet message boards', Journal of Language and Social Psychology, Vol. 27, No. 4, pp.409-421.

Kohn, A. and Neiger, M. (2007) 'To talk and talkback: analyzing the rhetoric of talkbacks in online journalism', Online Newspapers in Israel, Jerusalem: Israel Democracy Institute, pp.321-350.

Manosevitch I. (2011) 'User generated content in the Israeli online journalism landscape', Israel Affairs, Vol. 173, pp.422-444.

Mishne, G.A. and Glance, N. (2006) 'Leave a reply: an analysis of weblog comments', $W W W 2006$ Workshop on Weblogging Ecosystem: Aggregation, Analysis and Dynamics, at WWW: The 15th International Conference on World Wide Web.

Monnoyer-Smith, L. and Wojcik, S. (2012) 'Technology and the quality of public deliberation: a comparison between on and offline participation', International Journal of Electronic Governance, Vol. 5, No. 1, pp.24-49.

Mouffe, C. (2000) The Deomcratic Paradox, Verso, London, New York.

Philipsen, G. (1987) 'The prospect for cultural communication', in Kincaid, D.L. (Ed.): Communication Theory: Eastern and Western Perspectives, Academic Press, San Diego, CA, pp.245-254.

Philipsen, G. (2002) 'Cultural communication', in Gudykunst, W.B. and Mody, B. (Eds.): Handbook of International and Intercultural Communication, 2nd ed., Sage, Thousand Oaks, CA, pp.51-67. 
Reich, Z. (2011) 'User comments: the transformation of participatory space', in Singer, J.B., Domingo, D., Heinonen, A., Hermida, A., Paulussen, S., Quandt, T., Reich, Z. and Vujnovic, M. (Eds.): Participatory Journalism: Guarding Open Gates at Online Newspapers, Blackwell Publishing Ltd., pp.96-117.

Townsend, R.M. (2009) 'Town meeting as a communication event: democracy's act sequence', Research on Language and Social Interaction, Vol. 42, No. 1, pp.68-89.

Vaisman, C.L. (2009) 'Blogs as public property media: defining the roles and assessing the influence of political blogging in Israel', in Russell, A. and Echchaibi, N. (Eds.): International Blogging: Identity, Politics, and Networked Publics, Peter Lang, New York, pp.111-133.

Verger, M. and Hermans, L. (2008) 'Analysing online political discussion: methodological considerations', Javnost-the Public, Vol. 15, No. 2, pp.37-56.

Wilson, S.M. and Peterson, L.C. (2002) 'The anthropology of online communities', Annual Review of Anthropology, Vol. 31, pp.449-467.

Wright, S. and Street, J. (2007) 'Democracy, deliberation and design: the case of online discussion forums', New Media \& Society, Vol. 9, No. 5, pp.849-869.

\section{Notes}

${ }^{1}$ As such, tokbek is part of the user-generated content (UGC) phenomenon. This communicative practice first appeared in Israel in 2001 (Manosevitch, 2011). European countries and the US adopted similar technological features at least half a decade later (Reich, 2011), making the Israeli online scene a pioneer in the adoption, use, and abuse of user comments in political discussions. For a more comprehensive account of the history of this arena see Galily (2008).

${ }^{2}$ Neiger and Kohn used the term 'anti-discourse', based on the Aristotelian notions of ethos, pathos, and logos, to describe antagonistic rhetorical relations between commenters and the journalistic texts to which they respond. In our study, we locate the meanings, forms, and functions of this anti-discourse in a specific sociocultural context.

${ }^{3}$ Posted at Ynet on 7/27/2006 under the title "This is a War, Not a Reality Show", at http://www.ynet.co.il/articles/0,7340,L-3282128,00.html (last entry, 24/10/13).

${ }^{4}$ See for example the documentary film The Tokbekists (2007, dir. Zvika Binder) that addresses the social scenery of the Israeli commenting community. Based on interviews with some 'professional' tokbek commenters, Binder suggests that membership in this community entails issues of interpersonal relations, social recognition, and prestige. Some commenters serve as opinion leaders, others as experts, and others as authors whose comments excel in their eloquence. This notion of membership deserves an ethnographic exploration that goes beyond the scope of our study. At the same time, it seems that tokbek discourse as an open arena for civic participation is not limited to such group membership. Moreover, if the particular tonalities of group membership do indeed exist, they were not heard over the cultural form, function, and meanings of the tokbek discourse that we analysed. This finding suggests that the features of tokbek discourse are pervasive within and between commenting threads, regardless of the variability of in-group identification.

${ }^{5}$ Hebrew reads from right to left. Due to space limitations, we cannot discuss the formatting of the webpage, the modalities it affords, its graphics and the numbering of comments as conversational turns. These phenomena, while interesting, are not central to our discussion.

${ }^{6}$ Linguistically, Israeli Hebrew uses root word-forms as its structure for creating word families. This feature facilitated the adaption of tokbek as a Hebrew word.

${ }^{7}$ Posted at Ynet on 10/08/2003 under the title "Drums of Stumstum [a word play that refers to tamtam drums and signifies meaningless sound]", at http://www.ynet.co.il/home/0,7340,L-3632781769,00.html (last entry, 24/10/13).

${ }^{8}$ Posted at Haaretz Online on $1 / 20 / 2004$ as part of Alper's blog 'Connected', at http://www.haaretz.co.il/misc/1.940574 (last entry, 24/10/13). 
${ }^{9}$ Posted at NRG on 1/26/2010 under the title "To the Attention of Netanyahu Family We Are N-OT A-F-R-A-I-D”, at http://www.nrg.co.il/online/1/ART2/045/067.html (last entry, 24/10/13).

${ }^{10}$ Posted at YNET on 15/04/12 under the article "The People who didn't know how to ask", at http://www.ynet.co.il/articles/0,7340,L-4215946,00.html (last entry, 24/10/13).

${ }^{11}$ Posted at NRG on 21/02/12 under the article "Weinstein Netanyahu: The Recommendations of the Outpost Committee are not Binding by the Eighth", at http://www.nrg.co.il/online/ 1/ART2/339/065.html?hp=1\&cat=404 (last entry, 24/10/13).

Our citation of tokbek instances is organised in the following manner. The first line (marked in bold) is the comment's title. The second line indicates the content the commenter wrote in the 'identification' box (at times names, at times other content) and time of publication (hours follow 'military' time). The abbreviation ' $\mathrm{n}$ " $c$ ' that may appear in this line indicates that the comment has 'No Content'. The content of the comments appear below the name line. Italics were added to emphasise specific words and phrases. Our usage of gender terms in the analysis is based on the commenter's form of identification.

${ }^{12}$ Posted at Haaretz Online on 01/30/2012 under the article "Instead of 'Breaking the Silence': Ben Gvir Preached to the Sudents", at http://www.haaretz.co.il/news/education/1.1628919\# (last entry, 24/10/13).

${ }^{13}$ Posted at NRG in 21/02/12 under the article "Weinstein Netanyahu: The Recommendations of the Outpost Committee are not Binding by the Eighth", at http:/www.nrg.co.il/online/1/ART2/339/ 065.html?hp=1\&cat=404 (last entry, 24/10/13).

${ }^{14}$ Posted in Haaretz Online on 01/31/2012 under the article "Instead of 'Breaking the Silence': Ben Gvir Preached to the Sudents", at http://www.haaretz.co.il/news/education/1.1628919\# (last entry, 24/10/13).

${ }^{15}$ This difference was suggested by Scott Wright in the form of a personal comment in an earlier presentation of our analysis at Online Political Participation and its Critics - The International Symposium of the DEL Research Network Conference (Paris, June 2013). According to him, in comparison to Israeli tokbekists British commenters demonstrate a 'civilised' manner and 'deliberative' function whereby opinion is shaped in and through the communicative process.

${ }^{16}$ It should be noted that a centrist political identity of an 'in-betweener' who rejects the extreme instances of both leftists and rightists is also possible within the framework of tokbek discourse, albeit less salient. One example: "I have no problem with leftists as long as they are not extremists and I have no problems with rightists as long as they are not extremists". In terms of function, such declarations also fall into the analytic category of 'inverted identity politics'.

${ }^{17}$ Posted at Ynet on 4/24/2012 under the article "A Lesson in Citizenship in the Knesset: Fascism at the Door", at http://www.ynet.co.il/articles/0,7340,L-4219665,00.html (last entry, 24/10/2013). 